\title{
Fat mass and obesity associated (FTO) gene influences skeletal muscle phenotypes in non-resistance trained males and elite rugby playing position
}

S. M. Heffernan ${ }^{1 *}$, G. K. Stebbings ${ }^{1}$, L. P. Kilduff², R. M. Erskine ${ }^{3,4}$, S. H. Day ${ }^{1}$, C. I. Morse ${ }^{1}$, J. S. McPhee ${ }^{12}$, C. J. Cook ${ }^{2,6}$, B. Vance ${ }^{7}$, W. J. Ribbans ${ }^{5}$, S. M. Raleigh ${ }^{5}$, C. Roberts ${ }^{8,9}$, M. A. Bennett ${ }^{2}$, G. Wang ${ }^{10}$, M. Collins ${ }^{11}$, Y. P. Pitsiladis ${ }^{10}$ and A. G. Williams ${ }^{1,4}$

\begin{abstract}
Background: FTO gene variants have been associated with obesity phenotypes in sedentary and obese populations, but rarely with skeletal muscle and elite athlete phenotypes.

Methods: In 1089 participants, comprising 530 elite rugby athletes and 559 non-athletes, DNA was collected and genotyped for the FTO rs9939609 variant using real-time PCR. In a subgroup of non-resistance trained individuals (NT; $n=120$ ), we also assessed structural and functional skeletal muscle phenotypes using dual energy $x$-ray absorptiometry, ultrasound and isokinetic dynamometry. In a subgroup of rugby athletes $(n=77)$, we assessed muscle power during a countermovement jump.
\end{abstract}

Results: In NT, $\Pi$ genotype and T allele carriers had greater total body (4.8\% and $4.1 \%$ ) and total appendicular lean mass (LM; 3.0\% and 2.1\%) compared to AA genotype, with greater arm LM (0.8\%) in T allele carriers and leg LM (2.1\%) for T, compared to AA genotype. Furthermore, the T allele was more common (94\%) in selected elite rugby union athletes (back three and centre players) who are most reliant on LM rather than total body mass for success, compared to other rugby athletes $(82 \% ; P=0.01, \mathrm{OR}=3.34)$ and controls $(84 \% ; P=0.03$, $\mathrm{OR}=2.88)$. Accordingly, these athletes had greater peak power relative to body mass than other rugby athletes $\left(14 \% ; P=2 \times 10^{-6}\right)$.

Conclusion: Collectively, these results suggest that the T allele is associated with increased LM and elite athletic success. This has implications for athletic populations, as well as conditions characterised by low LM such as sarcopenia and cachexia.

Keywords: RugbyGene project, IRX3, Lean mass

\section{Background}

Fat mass and obesity associated (FTO) is the most investigated gene in obesity and has complex molecular mechanisms that are yet to be elucidated. Recent genome-wide association studies (GWAS) have identified several common single nucleotide polymorphisms (SNP) in the human FTO gene associated with obesity,

\footnotetext{
* Correspondence: shane.heffernan@stu.mmu.ac.uk

${ }^{1}$ MMU Sports Genomics Laboratory, Manchester Metropolitan University,

Crewe Green Road, Crewe CW1 5DU, UK

Full list of author information is available at the end of the article
}

body mass index BMI; [1], cardiovascular disease and hypertension $[2,3]$. These FTO SNPs, which are in strong linkage disequilibrium $\left(r^{2}>0.80\right)$, are located in a cluster on the first intron of the gene on chromosome 16 and consequently exhibit similar obesityrelated traits [4]. Thus, within different FTO variants, those alleles that have been positively associated with obesity-related phenotypes are referred to as risk alleles, while those negatively associated with such traits are referred to as protective alleles. Homozygotes for the minor risk allele consistently demonstrate greater 
BMI and body mass (3-10 kg) in comparison to protective allele carriers [5,6]. This greater body mass is likely to be adipose tissue [7-11], although there exist some suggestions of greater lean mass (LM) in addition to fat mass $[9,12]$ and independent of fat intake and physical activity [9]. This suggests that FTO genotype may be related to muscle properties and is supported by evidence from a large UK twin study that related FTO SNPs with body composition while controlling for lean mass and fat mass (separately and combined). The authors concluded that FTO SNP associations with body size were a composite of both lean and fat mass, not fat mass alone [13].

Environmental lifestyle factors (diet and physical activity) have also been investigated for FTO gene-environment interactions. Risk allele carriers are more likely to choose a high fat diet than protective allele carriers [11, 14, 15]. However, with administration of a high protein diet $(25 \%$ energy intake) risk allele carriers demonstrated a greater reduction in body mass, fat mass and percentage body fat [16], due to greater appetite suppression than in protective allele carriers [17]. Additionally, physically active risk allele carriers have a $30 \%$ reduction in likelihood of becoming obese and have $36 \%$ less body fat compared to inactive risk allele carrying individuals [18]. In contrast, data from the HERITAGE Family Study showed that following 20 weeks of endurance training, protective allele carriers exhibited reductions in fat mass three times greater than risk allele homozygotes [19]. Interestingly, when comparing normal weight and obese individuals who participate in sport, no differences in FTO genotype were observed $(P=0.97)$, which was contrasted by those not participating $P=0.02$; [20]. Considering the attenuation of $F T O$-associated obesity with environmental factors and the greater FTO-associated LM reported in obese populations [9, 12], investigating LM and associated phenotypes in healthy, non-obese, nonresistance trained individuals and habitually trained elite athletes would be worthwhile.

To date, there have been no investigations of in vivo skeletal muscle phenotypes in trained or non-resistance trained populations for associations with FTO genotype. Eynon et al. [21] investigated FTO rs9939609 in three European cohorts of power $(n=258 ; 58.3 \%$ elite $)$ and endurance athletes $(n=266 ; 57.1 \%$ elite) from a variety of sporting disciplines - but identified no associations. This lack of association was likely due to the considerable differences in physiological demand between the various athletic disciplines included, plus further variability in the standard of athlete. We have recently shown the ability of genetic research in a single sport with player roles that differ distinctly, namely rugby union (RU), to reveal context-specific competitive advantages provided by particular alleles [22]. Therefore, as RU includes athletes of remarkably distinct anthropometric and body composition phenotypes, elite RU provides a unique opportunity to investigate $F T O$ in individuals at the extreme upper end of physical fitness [23].

Therefore, the main aims of the present study were to (1) investigate any association of FTO rs9939609 with body composition and muscle structural and functional parameters in a homogenous, healthy, non-obese nonresistance trained population (2) investigate whether FTO rs9939609 genotype differed between elite rugby athletes and a control population, and/or between RU player positions. Based on prior data in obese populations, it was hypothesised that the rs9939609 risk (A) allele would be associated with greater body mass, fat mass, BMI, LM, muscle volume and muscle strength in non-resistance trained individuals. Secondly, for the elite rugby cohort, it was hypothesised that the FTO A allele would be overrepresented in player positions typically requiring greater body and muscle mass while the protective ( $\mathrm{T}$ ) allele would be more common in positions requiring a lean phenotype.

\section{Method \\ Participants}

A total of 1089 individuals were recruited and gave written informed consent to participate in the present study. The total sample comprised elite Caucasian male rugby athletes $(n=530$; height $1.85(0.07) \mathrm{m}$, mass 101 (14) kg, age 29 (7) yr, BMI 29.4 (3.7) $\mathrm{kg} \cdot \mathrm{m}^{-2}$; mean (standard deviation (SD)) including $73 \%$ British, $16 \%$ South African, $7 \%$ Irish and 4\% from other nationalities and non-athlete Caucasian control participants (male and female; $n=$ 559; height $1.75(0.10) \mathrm{m}$, mass 75 (13) $\mathrm{kg}$, age 29 (16) yr, BMI $24.5(3.6) \mathrm{kg} \cdot \mathrm{m}^{-2}$ ) including $86 \%$ British, $12 \%$ South African, 1\% Irish and 1\% from other nationalities. Athletes were considered elite if they had competed regularly (> 5 matches) since 1995 in the highest professional league in the UK, Ireland or South Africa for RU or the highest professional league in the UK for rugby league (RL). Of the RU athletes, $52.7 \%$ had competed at an international level for a "High Performance Union" (Regulation 16, worldrugby.org) and $43.2 \%$ of RL had competed at international level. All data for the athlete group's international status were confirmed as of 1st June 2016. Furthermore, within the rugby cohort, a subsample $(n=77)$ were examined for performance-related muscle phenotypes. Within the control group were a subgroup of non-resistance trained healthy males (NT; Table 1). NT participants were aged $18-39$ years, had a BMI $18.5-30 \mathrm{~kg} \cdot \mathrm{m}^{-2}$, had not undertaken any structured resistance training in the preceding 12 months and had no history of neurological or musculoskeletal disorders. Additionally, only those participants undertaking less than $3 \mathrm{~h}$ of low-to-moderate physical activity per week, assessed via questionnaire [24], were included. 
Table 1 Descriptive, morphological and functional characteristics of all participants and genetic frequency, in the non-resistance trained (NT) cohort

\begin{tabular}{|c|c|c|c|c|c|c|}
\hline Phenotype & All $(n=120)$ & AA $(n=18)$ & AT $(n=58)$ & $\Pi(n=44)$ & $\Pi+\mathrm{AT}(n=102)$ & $P$ values Additive (Recessive) \\
\hline Height (m) & $1.79(0.06)$ & $1.80(0.06)$ & $1.78(0.07)$ & $1.80(0.06)$ & $1.79(0.07)$ & $0.15(0.48)$ \\
\hline Mass (kg) & $75.0(10.0)$ & $81.0(8.1)$ & $74.2(10.3)$ & $73.5(9.6)$ & $73.9(10.0)$ & $0.03(0.02)$ \\
\hline BMI $\left(\mathrm{kg} \quad \mathrm{m}^{-2}\right)$ & $23.4(2.7)$ & $25.1(2.6)$ & $23.5(2.8)$ & $22.6(2.4)$ & $23.1(2.6)$ & $0.02(0.02)$ \\
\hline Age (years) & $20.6(2.3)$ & $21.6(2.8)$ & $20.9(2.4)$ & $19.7(1.6)$ & $20.4(2.1)$ & $0.02(0.08)$ \\
\hline Fat mass (\%) & $21.5(5.2)$ & $23.3(5.5)$ & $21.8(5.2)$ & $20.3(4.8)$ & $21.2(5.1)$ & $0.09(0.11)$ \\
\hline LM (\%) & $73.5(5.9)$ & $70.3(6.3)$ & $73.3(5.6)$ & $75.1(5.8)$ & $74.4(5.6)$ & $0.04(0.04)$ \\
\hline Total appendicular LM (\%) & $33.4(3.8)$ & $31.6(3.5)$ & $33.0(3.7)$ & $34.6(3.7)$ & $33.7(3.7)$ & $0.04(0.05)$ \\
\hline Arm LM (\%) & $8.5(1.2)$ & $7.9(1.0)$ & $8.6(1.3)$ & $8.7(1.1)$ & $8.7(1.2)$ & $0.06(0.04)$ \\
\hline Leg LM (\%) & $24.8(2.9)$ & $23.7(3.1)$ & $24.4(2.8)$ & $25.8(2.9)$ & $25.0(2.9)$ & $0.04(0.10)$ \\
\hline$V_{V L}\left(\mathrm{~cm}^{3}\right)$ & $566(86)$ & $585(81)$ & $550(86)$ & $580(85)$ & $563(86)$ & $0.20(0.61)$ \\
\hline$V L A C S A\left(\mathrm{~cm}^{2}\right)$ & $21.4(2.5)$ & $21.9(2.8)$ & $21.0(2.4)$ & $21.9(2.5)$ & $21.4(2.5)$ & $0.20(0.86)$ \\
\hline VL PCSA $\left(\mathrm{cm}^{2}\right)$ & $71.7(13.9)$ & $71.2(13.9)$ & $72.0(13.7)$ & $71.5(11.0)$ & $71.8(12.6)$ & $0.97(0.61)$ \\
\hline Isometric $\mathrm{MVC}_{\mathrm{KE}}$ torque $(\mathrm{N} \quad \mathrm{m})$ & $272(53)$ & $285(38)$ & $271(63)$ & $268(45)$ & $270(56)$ & $0.50(0.25)$ \\
\hline$V L$ specific force $\left(\mathrm{N} \cdot \mathrm{cm}^{-2}\right)$ & $21.6(2.6)$ & $22.3(2.5)$ & $21.6(2.5)$ & $21.1(2.8)$ & $21.4(2.6)$ & $0.50(0.25)$ \\
\hline
\end{tabular}

Data are mean (SD)

$B M I$, body mass index, $L M$ lean mass, $V L$ vastus lateralis, $A C S A$ anatomical cross sectional area, $P C S A$ physiological cross-sectional area, $M V C_{K E}$ maximal voluntary contraction, $V_{V L}$ vastus lateralis muscle volume

\section{Procedures}

\section{Muscle properties in NT}

An isokinetic dynamometer (Cybex Norm, Cybex International Inc., NY, USA) was used to assess maximal isometric knee extension $\left(\mathrm{MVC}_{\mathrm{KE}}\right)$ and maximal isometric knee flexion $\left(\mathrm{MVC}_{\mathrm{KF}}\right)$ torque at knee joint angles of $70^{\circ}$, $80^{\circ}$ and $90^{\circ}$ (full knee extension $=0^{\circ}$ ). The angle of peak torque was taken as the optimal knee joint angle and used to estimate antagonist muscle co-activation during MVC, which assumed a linear relationship between biceps femoris EMG activity and knee flexion torque [25]. Together with antagonist co-activation, quadriceps femoris (QF) voluntary activation capacity, determined using the interpolated twitch technique [26], allowed for the calculation of net $\mathrm{MVC}_{\mathrm{KE}}$ torque. Subsequently, patella tendon moment arm length $\left(d_{\mathrm{PT}}\right)$ was measured using dual energy x-ray absorptiometry DXA; [27] and patella tendon force calculated as net $\mathrm{MVC}_{\mathrm{KE}}$ torque/ $d_{\mathrm{PT}}$. The contribution of the vastus lateralis (VL) muscle $\left(\mathrm{MF}_{\mathrm{VL}}\right)$ to patella tendon force was calculated by estimating the relative physiological cross-sectional area (PCSA) of the VL as $\sim 21 \%$ of the QF [28]. VL muscle architecture (fascicle length, $L_{\mathrm{f}}$ and pennation angle, $\theta$ ) was measured at $50 \%$ of $\mathrm{VL}$ length during $\mathrm{MVC}_{\mathrm{KE}}$ at the optimal knee joint angle using ultrasound (AU5, Esaote, Italy) and VL fascicle force estimated as $\mathrm{MF}_{\mathrm{VL}} /$ cosine $\theta$ [29]. At rest, ultrasound was also used to obtain a series of transverse plane scans at $50 \%$ of VL muscle length from the medial to lateral borders, which were contour matched to determine VL anatomical cross-sectional area [ACSA; 29]. With VL length and VL ACSA used to estimate VL volume $\left(V_{\mathrm{VL}}\right)$ as previously [30]. Subsequently, VL PCSA was calculated as $V_{\mathrm{VL}} /$ $L_{\mathrm{f}}$ and, VL specific force calculated by dividing VL fascicle force by VL PCSA [29]. Finally, quantification of whole body and appendicular LM was completed using DXA (Hologic Discovery: Vertec Scientific Ltd, UK) following a $12 \mathrm{~h}$ overnight fast. Participants lay in a supine position, avoiding any contact between the trunk and the appendicular mass during a $7 \mathrm{~min}$ whole body scanning procedure (effective dose, 8.4 $\mu \mathrm{Sv}$ ). Appendicular lean mass was estimated from the DEXA as the total muscle mass of both the upper and lower limbs, where LM is body mass excluding fat and bone mass.

\section{Muscle power in RU athletes}

Using a portable force platform (Type 92866AA, Kistler, Germany) peak power output (PPO) was determined during a bilateral countermovement jump (CMJ) according to methods described previously [31]. Body mass and the vertical component of the ground reaction force during the CMJ (sampled at $1000 \mathrm{~Hz}$ ) were used to determine instantaneous velocity and displacement of the participant's centre of gravity. Instantaneous power output was determined using the following equation: Power $(W)=$ vertical GRF $(N) x$ vertical velocity of centre of gravity $\left(\mathrm{m} \cdot \mathrm{s}^{-1}\right)$, with the highest value produced deemed the PPO.

\section{Sample collection and genotyping}

Description of all molecular procedures have previously been described in detail [22]. Briefly, blood ( $70 \%$ of all 
samples), saliva $(\sim 25 \%)$ or buccal swab samples $(\sim 5 \%)$ were obtained via the following protocols. Blood was drawn from a superficial forearm vein into an EDTA tube and stored in sterile tubes at $-20^{\circ} \mathrm{C}$ until processing. Saliva samples were collected into Oragene DNA OG-500 collection tubes (DNA Genotek Inc., Ontario, Canada) according to the manufacturer's protocol and stored at room temperature until processing. Sterile buccal swabs (Omni swab, Whatman, Springfield Mill, UK) were rubbed against the buccal mucosa of the cheek for approximately $30 \mathrm{~s}$. Tips were ejected into sterile tubes and stored at $-20^{\circ} \mathrm{C}$ until processing. DNA isolation and genotyping were performed in the MMU, University of Glasgow, University of Cape Town (DNA isolation only) and University of Northampton laboratories. The majority of samples were processed and genotyped in the MMU laboratory, including all samples within NT. At MMU and Glasgow, DNA isolation was performed using the QIAamp DNA Blood Mini kit and standard spin column protocol, following the manufacturer's instructions (Qiagen, West Sussex, UK). Briefly, $200 \mu L$ of whole blood/saliva, or one buccal swab, was lysed, incubated, the DNA washed and the eluate containing isolated DNA stored at $4^{\circ} \mathrm{C}$. In Cape Town, DNA was isolated from whole blood using a different protocol [32] during which samples were lysed, centrifuged, the DNA washed and samples stored at $-20^{\circ} \mathrm{C}$. Genotyping of DNA isolated in Cape Town was performed in Glasgow. At Northampton, DNA was isolated from whole blood using Flexigene kits (Qiagen). Briefly, samples were lysed, DNA precipitated and washed, with samples stored at $-20^{\circ} \mathrm{C}$.

Genotyping in all three genotyping centres was performed on FTO (rs9939609). Briefly, in the Glasgow laboratory $10 \mu L$ Genotyping Master Mix (Applied Biosystems, Paisley, UK), $1 \mu L$ SNP-specific TaqMan assay (Applied Biosystems), $6 \mu L$ nuclease-free $\mathrm{H}_{2} \mathrm{O}$ and $3 \mu L$ DNA solution ( $\sim 9$ ng DNA) were added per well. In the Northampton laboratory, genotyping was performed by combining 10 $\mu L$ of Genotyping Master Mix, $8 \mu L \mathrm{H}_{2} \mathrm{O}, 1 \mu L$ assay mix with $1 \mu L$ of purified DNA ( 10 ng). In both laboratories, PCR was performed using a StepOnePlus real-time detector (Applied Biosystems). Briefly, after an initial 10 min at $95^{\circ} \mathrm{C}, 40$ cycles of denaturation at $92^{\circ} \mathrm{C}$ for $15 \mathrm{~s}$ then annealing and extension at $60^{\circ} \mathrm{C}$ for $1 \mathrm{~min}$ were used. Genotyping calls were performed using StepOnePlus software version 2.3 (Applied Biosystems). At MMU, $5 \mu L$ Genotyping Master Mix, $4.3 \mu L \mathrm{H}_{2} \mathrm{O}, 0.5 \mu L$ assay mix and $0.2 \mu L$ of purified DNA ( $9 \mathrm{ng}$ ) were used in each reaction for samples derived from blood and saliva. For DNA derived from buccal swabs, $5 \mu L$ Genotyping Master Mix was combined with $3.5 \mu L \mathrm{H}_{2} \mathrm{O}, 0.5 \mu L$ assay mix and $1 \mu L$ DNA solution ( $\sim 9$ ng DNA). Either a Chromo4 (Bio-Rad, Hertfordshire, UK) or StepOnePlus real-time PCR system was used. Briefly, after an initial $10 \mathrm{~min}$ at $95^{\circ} \mathrm{C}, 40$ cycles of denaturation at $92^{\circ} \mathrm{C}$ for $15 \mathrm{~s}$ then annealing and extension at $60^{\circ} \mathrm{C}$ for $1 \mathrm{~min}$ were used. Genotyping calls were performed using Opticon Monitor software version 3.1 (Bio-Rad) or StepOnePlus software version 2.3. The Taqman assay included VIC and FAM dyes that indicated A and $\mathrm{T}$ alleles on the forward DNA strand, respectively. Thus, VIC/FAM were interpreted as: $5^{\prime}$-GTGAATTT[A/T] GTGATGCA-3'.

\section{RU positional groups}

As established previously [22], to compare genotype and allele frequencies within the RU group, athletes were allocated to subgroups; forwards (props, hookers, locks, flankers, number eights) and backs (scrum halves, fly halves, centres, wings, full backs). Also, due to diverse physiological demands within RU [33, 34], athletes were further divided into established positional groups according to their movement patterns [33]; front five (props, hookers, locks), back row (flankers, number eights), half backs (scrum halves, fly halves), back three (wings and full backs) and centres. For example, in one study the front five travelled $\sim 136$ $\mathrm{m}$ at $>5 \mathrm{~m} \cdot \mathrm{s}^{-1}$ compared to $\sim 566 \mathrm{~m}$ for the back three [35]. Comparisons between positions were not performed for the RL cohort due to low statistical power when it was subdivided.

\section{Data analysis}

SPSS for Windows version 22 (SPSS Inc., Chicago, IL) software was used to conduct statistical analyses. Oneway analysis of variance (ANOVA) was used to compare height, mass, BMI, age and PPO between sample populations and genotype groups. When genotype groups were compared using a recessive model, an independent samples t-test was used. Furthermore, genotype effects on muscle phenotypes of interest were assessed for linear trend. Pearson's $x^{2}$ tests compared genotype and allelic frequencies between athlete and control groups and between RU positional subgroups. There were 30 comparisons for genotype frequency between groups and 28 tests of genotype differences in phenotype in NT that were subjected to Benjamini-Hochberg corrections to control false discovery rate and corrected probability values are reported [36]. Where appropriate, odds ratio (OR) and eta squared $\left(\eta_{\mathrm{P}}^{2}\right)$ were calculated to estimate effect size. Alpha was set at 0.05 .

\section{Results}

Genotype calling was successful in all samples. There was $100 \%$ agreement among reference samples genotyped in the three genotyping centres, i.e. Glasgow, Northampton and MMU laboratories. Genotype frequencies were in Hardy-Weinberg equilibrium for 
the entire control group $(P=0.871)$, NT $(P=0.988)$ and athlete groups (RL, $P=0.183$; RU, $P=0.076$ ).

\section{Non-resistance trained (NT)}

The AA genotype group had greater body mass, BMI and age but not height compared to other genotype groups (Table 1). There were genotype differences for total body $\left(\eta_{\mathrm{P}}^{2}=0.072\right)$, total appendicular $\left(\eta_{\mathrm{P}}^{2}=0.075\right)$ and leg $\left(\eta_{\mathrm{P}}^{2}=0.078\right) \mathrm{LM}$, with tendencies for arm LM $(P$ $\left.=0.06, \eta_{\mathrm{P}}^{2}=0.054\right)$ and total fat mass $\left(P=0.09, \eta_{\mathrm{P}}^{2}=\right.$ $0.024)$. T-allele carriers demonstrated greater total body (5.3\%), appendicular (6.7\%) and arm (9.8\%), but not leg $(P=0.10)$ LM than AA homozygotes. There were no differences in muscle size, torque or specific force variables (Table 1).

\section{Athletes}

Athletes were taller and heavier $(P<0.05)$ but not older $(P>0.05)$ than controls. There were no genotype frequency differences between athletes (RL and RU combined; $P=0.16)$, RL $(P=0.36)$, RU $(P=0.16)$ and controls (only additive models presented).

In terms of player position, backs had a greater frequency of $\mathrm{T}$ allele carriers than forwards $(P=0.03$, Table 2, Fig. 1) and showed greater odds of being $\mathrm{T}$ allele carriers than AA genotype $(\mathrm{OR}=1.84$, Table 3$)$. When combined, the back three and centres group contained less AA homozygotes and more $\mathrm{T}$ allele carriers $(P=$ $0.03, P=0.02$, respectively; Fig. 1 a and Table 2 ) than controls. Additionally, controls had more than twice the odds of being AA than the back three and centres group, with greater odds of $\mathrm{T}$ allele carriers in the back three and centres than controls (Table 3). Compared to forwards and all other RU athletes, TT genotype $(P=0.03$; $P=0.03$, respectively) and T allele carriers $(P=0.02 ; P=$ 0.02 , respectively) were more common in the back three and centres group (Fig. 1a and Table 2). Likewise, forwards and all other RU athletes had greater than three times the odds of being AA genotype than the back three and centres group, with greater odds of $\mathrm{T}$ allele carriers in the back three and centres group than forwards and all other RU athletes (Table 3). Furthermore, the back three and centres group showed a greater $\mathrm{T}$ allele frequency than both forwards and all other RU athletes (Fig. 1b) and almost one and a half times greater odds of possessing the $\mathrm{T}$ allele (Table 3 ).

\section{Muscle power}

While PPO tended to be greater in back row players with lowest power in the halfbacks $(5792$ vs $5000 \mathrm{~W}$; $P$ $=0.09$ ), PPO relative to body mass did differ according to playing position (Table 4). The centre and back 3 players $\left(59 \mathrm{~W} \cdot \mathrm{kg}^{-1}\right)$ were $9.8 \%$ more powerful than back row (54 W. $\mathrm{kg}^{-1} ; P=0.025$ ) and $20.2 \%$ more powerful than front 5 players $\left(47 \mathrm{~W} \cdot \mathrm{kg}^{-1} ; P=6 \times 10^{-7}\right.$; Table 4).

\section{Discussion}

We have shown that individuals possessing the FTO rs9939609 T allele and TT genotype had greater LM, while no differences in leg muscle size or strength were observed (Table 1), thus rejecting our first hypothesis that the risk (A) allele would be associated with greater LM and muscle volume in a healthy non-resistance trained population. That greater LM in T allele and TT genotype individuals was observed despite A allele carriers having greater body mass and BMI as reported previously $[5,6]$. In agreement with our second hypothesis, we report a greater $\mathrm{T}$ allele and TT genotype frequency in elite rugby athlete playing positions more reliant on a lean phenotype for success [37], while the A allele is more common in those positions where total body mass is more important [38]; Fig. 1, Tables 2 and 3. The ability to rapidly produce high levels of power relative to body mass using the leg musculature was greater in those playing positions more reliant on a lean phenotype (Table 4) and is in agreement with previously published data of elite RU players [39]. One possible biological mechanism underlying the present results may be the action of the iroquois homeobox 3 (IRX3) protein through its FTO genomic loci interaction.

Table 2 Genotype and allele distribution of controls and athletes separated by code (RL and RU) and into positional subgroups for $\mathrm{RU}$, presented as genotype/allele counts followed by percentage in parentheses

\begin{tabular}{lllllllllll}
\hline Genotype/allele & All athletes & RL athletes & RU athletes & Controls & Forwards & Backs & Front 5 & Back row & Half backs & Back 3 and centres \\
\hline FTO & & & & & & & & & & \\
AA & $80(15.1)$ & $12(13.6)$ & $69(15.3)$ & $90(16.1)$ & $48(18.5)$ & $21(11.0)$ & $30(17.0)$ & $18(21.7)$ & $13(17.8)$ & $8(6.8)^{*}$ \\
AT & $280(52.7)$ & $49(55.7)$ & $235(52.3)$ & $266(47.6)$ & $133(51.4)$ & $102(54.7)$ & $94(53.4)$ & $39(47.0)$ & $34(46.6)$ & $68(57.6)$ \\
T & $170(32.2)$ & $27(30.7)$ & $146(32.4)$ & $203(36.3)$ & $78(30.1)$ & $68(34.3)$ & $52(29.6)$ & $26(31.3)$ & $26(35.6)$ & $42(35.6)^{\ddagger}$ \\
Total & 530 & 88 & 450 & 559 & 259 & 191 & 176 & 83 & 73 & 118 \\
A allele & $440(41.5)$ & $73(41.5)$ & $375(41.4)$ & $446(39.9)$ & $229(44.2)$ & $144(37.7)$ & $154(43.7)$ & $75(45.2)$ & $60(41.1)$ & $84(35.6)^{\ddagger}$ \\
T allele & $620(58.5)$ & $103(58.5)$ & $527(58.6)$ & $672(60.1)$ & $289(55.8)$ & $238(62.3)$ & $198(56.3)$ & $91(54.8)$ & $86(58.9)$ & $152(64.4)$ \\
\hline
\end{tabular}

Eight athletes competed in both elite RL and RU and were included in both groups that were analysed separately. ${ }^{*}$ Different from controls $(P<0.04)$. ${ }^{\ddagger}$ Different from forwards $(P=0.03)$ 

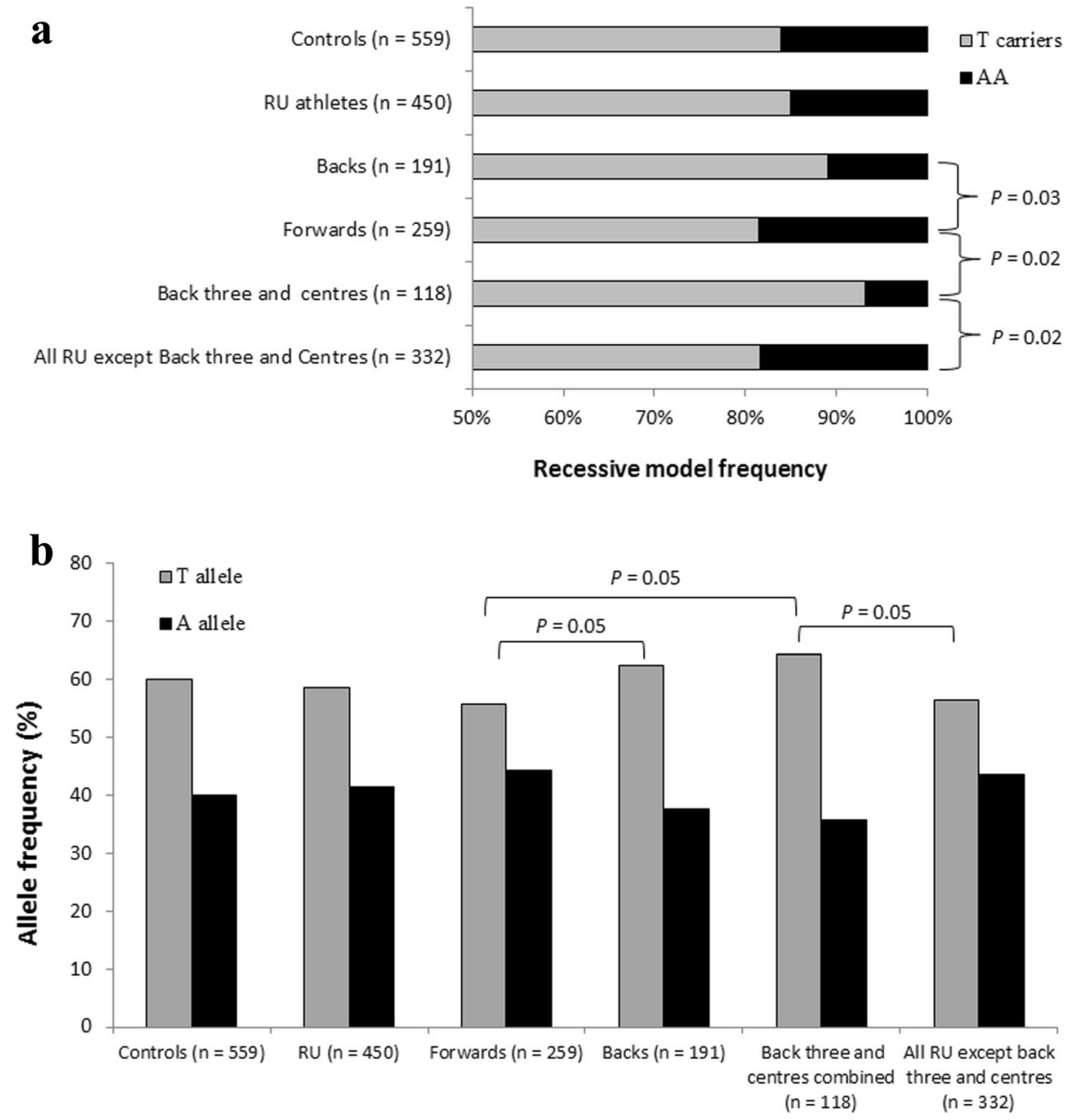

Fig. 1 FTO genotype data of athletes and controls. a Recessive model. Grey bars are T allele carriers, black bars are AA genotypes. b Allele frequency for selected subgroups. Grey bars represent the T allele, black bars represent the A allele

Table 3 Odds Ratio statistics for RU athlete status by playing position for FTO genotype (TT/AA), allele (T/A) and recessive (T/AA) genetic models

\begin{tabular}{llcll}
\hline Positional comparison & $\begin{array}{l}\text { Genetic } \\
\text { model }\end{array}$ & $\begin{array}{l}\text { Odds } \\
\text { ratio }\end{array}$ & $\begin{array}{l}\text { 95\% Confidence } \\
\text { interval }\end{array}$ & $P$ value \\
\hline Backs $\vee$ Forwards & T/AA & 1.84 & $1.06-3.19$ & 0.029 \\
Back 3 and centres & TT/AA & 2.33 & $1.05-5.16$ & 0.038 \\
v Controls & T/AA & 2.64 & $1.05-5.16$ & 0.012 \\
Back 3 and centres & TT/AA & 3.23 & $1.39-7.46$ & 0.006 \\
v Forwards & T/AA & 3.12 & $1.43-6.84$ & 0.004 \\
& T/A & 1.44 & $1.04-1.97$ & 0.026 \\
Back 3 and centres & TT/AA & 3.08 & $1.36-6.98$ & 0.007 \\
v all other RU athletes & T/AA & 3.09 & $1.43-6.68$ & 0.004 \\
& T/A & 1.37 & $1.01-1.86$ & 0.045 \\
Back 3 and centres & TT/AA & 2.98 & $1.17-7.59$ & 0.022 \\
v other backs & T/AA & 2.63 & $0.96-7.19$ & 0.060 \\
\hline
\end{tabular}

Until recently, little was known about the molecular basis for FTO SNP associations with any reported phenotype measure, because there was no association between FTO SNPs and expression of the FTO protein $[40,41]$. However, FTO has recently been found to influence IRX3 protein expression, through evolutionarily conserved long-range chromatin looping. Individuals possessing the protective FTO genotype/allele (TT/T) display lower IRX3 expression than AA homozygotes [42]. Furthermore, in contrast to IRX3 knockout (KO) mice, wild type mice exhibited similar FTO SNP risk (A) allele-associated phenotypes, such as greater BMI, body mass and body fat percentage [42]. Interestingly, IRX3 KO mice expended more energy, particularly at night, due to a greater browning of white fatty tissue [42] and recent findings show a link between brown fat and muscle developmental precursor Myf5 [43] which may provide a mechanism for the observation of greater LM in FTO $\mathrm{T}$ allele carriers in our NT cohort. Moreover, 
Table 4 Muscle power of RU athletes $(n=77)$ in positional groups. $P$ values are from comparisons of power between the four groups. Data are mean (SD)

\begin{tabular}{llllll}
\hline Phenotype & Front $5(n=32)$ & Back row $(n=14)$ & Half backs $(n=14)$ & Back 3 and centres $(n=17)$ & $P$ value \\
\hline Power $(\mathrm{W})$ & $5592(819)$ & $5687(858)$ & $4937(650)$ & $5579(569)$ & 0.030 \\
Relative Power $\left(\mathrm{W}^{\circ} \mathrm{kg}^{-1}\right)$ & $49.4(7.7)$ & $52.7(6.9)$ & $56.1(7.2)$ & $59.8(4.2)^{*}$ & $2 \times 10^{-5}$ \\
\hline
\end{tabular}

${ }^{*}$ Different from all other players $\left(P=8 \times 10^{-7}\right)$, including front $5\left(P=3 \times 10^{-6}\right)$ and back row $(P=0.005)$

using a transgenic mouse model (Rosa26 ${ }^{\text {Enr-Irx3 }}$ ) that disrupts IRX3 function whilst maintaining the genomic interaction between IRX3 and FTO (mimicking more accurately the human in vivo state than the aforementioned KO model), the authors showed retention of the KO model phenotype traits [42]. These FTO-IRX3 protein interactions suggest an explanation for the greater LM seen with the T allele carriers of the present study and possibly the association of the $\mathrm{T}$ allele with muscle power relative to body mass and its relationship with playing position in RU athletes (Tables 1, 2, and 4; Fig. 1).

The precise mechanisms of action of IRX3 in mammalian physiology are not fully understood, however the primary role of IRX3 in embryonic development and future actions in motor neuron restriction is relevant to this discussion. During neuronal development, IRX3 expression plays a key role in $\mathrm{N}$-tubulin development and initiation of neuronal programming. High levels of IRX3 protein promote early tissue development resulting in a lack of cell differentiation [44]. Thus, it is possible that because the FTO $\mathrm{T}$ allele is associated with lower IRX3 expression, greater early motor neuron differentiation might subsequently lead to greater LM - as we observed (Table 1). As such, for predeterminant neuronal cells to differentiate into a progenitor motor neuron domain and subsequently motor neurons, it appears IRX3 must be repressed by the microRNA mir-17-3p in order for OLIG2 to regulate the development of ventral spinal motor neurons [45]. Thus, as the expression of OLIG2 increases, the yield of motor neurons increases in tandem [46]. Considering FTO T allele carriers have a lower embryonic expression of IRX3, T allele carriers may have a predisposition for greater LM through enhanced life-long motor neuron availability via OLIG2 expression and therefore, may be at an advantage for certain forms of athletic ability and associated performance phenotypes (Tables 2, 3 and 4; Fig. 1). This rationale and the present results may represent a small portion of the $85 \%$ heritability of adult muscle neuronal function [47].

Recent associations between FTO variants and IGF-1, specifically that serum IGF-1 levels were greater in T allele carriers [48], may provide a second mechanism to explain the observed genotype differences in LM (Table 1). It is well known that IGF-1 is upregulated as a consequence of mechanical load/exercise and plays an important role in the cellular development of muscle hypertrophy [49].
Hence, T allele carriers, who in the NT group had significantly greater LM, may experience upregulation of IGF-1 compared to AA genotype counterparts. Furthermore, serum IGF-1 levels have been positively associated with quadriceps torque [50] and explosive muscle power [51] in older men. These data provide a further potential basis for our observation that RU athletes who require greater muscle power relative to body mass (Table 4) show a greater frequency of the $\mathrm{T}$ allele than other playing positions (Table 2 and 3; Fig. 1).

We observed a lower frequency of the AA genotype in back three and centre playing positions $(\mathrm{OR}=2.53$; Table 3), although there was no difference between the entire rugby cohort and controls. That latter observation is similar to that we reported previously regarding another genetic variant (ACTN3 rs1815739) where there was no difference between the entire rugby cohort and controls despite differences in genotype frequency according to playing position [22]. This again demonstrates the importance of defining athletes very carefully when conducting such comparisons. Global positioning system (GPS) data provide evidence for the relevance of our finding regarding FTO genotype in elite athletes. Jones et al. [35] showed that - at an elite competitive level - the back three and centre players express the greatest instantaneous and accumulative demands for exercise' (exertion index; EI) than all other athletes and spent more time at sprinting intensities. Thus, there is congruence between our dual observations of firstly greater LM in NT associated with the T allele, and secondly a greater frequency of the $\mathrm{T}$ allele in certain elite rugby athletes who rely on greater power outputs relative to body mass to be successful in those specific playing positions Table 3; [39].

These data suggest the relevance of the FTO rs9939609 $\mathrm{T}$ allele to muscle-related phenotypes and subsequently, athletic success. When considering the possible molecular mechanism from FTO via IRX3 to OLIG2 resulting in greater lifelong motor neuron availability, this may have implications for muscle size-related disorders such as sarcopenia and cachexia.

\section{Conclusions}

The presented data show a novel dimension of FTO genetic variation in human physiology, by investigating in vivo muscle phenotypes in a healthy non-resistance trained population and relating those data to the extreme upper 
end of human physical performance - i.e. elite athletes. We show that the FTO rs9939609 protective T allele may be responsible for part of the inherited component of the interindividual variability in LM. Furthermore, elite athletes who rely greatly on LM relative to total body mass for athletic success (RU back three and centre players, in this study) also seem more likely to carry a protective $T$ allele, have higher peak muscle power output relative to body mass and are likely to selected for appropriate playing positions as a result of these and other phenotypes. It is possible that this association between the FTO rs9939609 SNP, via LM, and athletic success, could be a result of the interaction with IRX3 in embryonic development of motor neuron patterning and the IGF-1 muscle development pathway. The strengths of the presented paper are the two-layered study design (NT and elite athlete cohorts) and the combination of muscle functional phenotypes with case-control data. While the finding that FTO genotype differs among elite rugby playing positions is a new insight, FTO is only one of many variants (most others unknown) that contribute to this phenotype and as such should not be used for talent identification at this time. Replication is necessary for each cohort using comparable methods, and future experimental focus should be on the proposed biological pathways of these $F T O$ associations with muscle phenotypes.

\section{Abbreviations}

ACSA: Anatomical cross-sectional area; BMI: Body mass index;

CMJ: Countermovement jump; DXA: Dual energy x-ray absorptiometry;

FTO: Fat mass and obesity; IGF-1: Insulin-like growth factor 1; IRX3: Iroquois

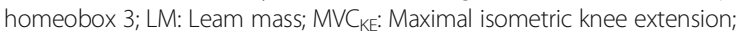
$M \mathrm{MV}_{\mathrm{KF}}$ : Maximal isometric knee flexion; NT: Non-resistance trained; OLIG2: Oligodendrocyte transcription factor; PCSA: Physiological crosssectional area; PPO: Peak power output; QF: Quadriceps femoris; RL: Rugby league; RU: Rugby union; VL: Vastus laterals; $V_{V L}: V L$ muscle volume

\section{Acknowledgements}

The authors wish to thank all athletes, their respective scientific support staff and the control participants for their time and willingness to participate in this research. We would like to thank Louis El Khoury for his technical assistance at the University of Northampton and Ben Davies for assistance in participant recruitment.

\section{Funding}

Research funded by Manchester Metropolitan University.

\section{Availability of data and materials}

Data used to generate statistical conclusions are presented in the published article. Researchers may reasonably request additionally data and materials from the RugbyGene project, via contacting the corresponding author.

\section{Authors' contributions \\ Listed alphabetically: MC, SD, RE, SH, LK, YP, AW and GW conceived and designed the study. MB, CC, MC, RE, SH, LK, CM, JMC, CR, SR, WR, GS, BV, AW and GW contributed to data collection. SH and AW analysed data and drafted the manuscript. All authors contributed to interpretation of data, revised the article critically for important intellectual content and approved the final version of the manuscript.}

\section{Competing interests}

The authors declare that they have no competing interests.

\section{Consent for publication}

Not applicable.

\section{Ethics approval and consent to participate}

Ethical approval was granted by the ethics committees of Manchester Metropolitan University, Glasgow University, University of Cape Town and University of Northampton and all experimental procedures complied with the Declaration of Helsinki (2003). All participates gave written informed consent to take part in the present study and for the results to be published.

\section{Twitter}

Follow the RugbyGene project at @RugbyGeneStudy.

\section{Author details}

${ }^{1}$ MMU Sports Genomics Laboratory, Manchester Metropolitan University, Crewe Green Road, Crewe CW1 5DU, UK. ${ }^{2}$ A-STEM, College of Engineering, Swansea University, Swansea, UK. ${ }^{3}$ Research Institute for Sport \& Exercise Sciences, Liverpool John Moores University, Liverpool, UK. Institute of Sport, Exercise and Health, University College London, London, UK. ${ }^{5}$ Centre for Physical Activity and Chronic Disease, Institute of Health and Wellbeing, University of Northampton, Northampton, UK. ${ }^{6}$ School of Sport, Health and Exercise Sciences, Bangor University, Bangor, UK. Institute of Cardiovascular \& Medical Sciences University of Glasgow, Glasgow, UK. ${ }^{8}$ Medical and Scientific Department, South African Rugby Union, Cape Town, South Africa. ${ }^{9}$ Discipline of Sports Science, Faculty of Health Sciences, University of Kwazulu-Natal, Durban, South Africa. ${ }^{10}$ FIMS Reference Collaborating Centre of Sports Medicine for Anti-Doping Research, University of Brighton, Brighton, UK. ${ }^{11}$ Division of Exercise Science and Sports Medicine, Department of Human Biology, University of Cape Town (UCT), Cape Town, South Africa.

${ }^{12}$ School of Healthcare Science, Manchester Metropolitan University, Manchester, UK.

Received: 18 August 2016 Accepted: 10 January 2017

Published online: 19 January 2017

\section{References}

1. Jacobsson JA, Schiöth $H$, Fredriksson R. The impact of intronic single nucleotide polymorphisms and ethnic diversity for studies on the obesity gene FTO. Obes Rev. 2012;13(12):1096-109.

2. He D, Fu M, Miao S, Hotta K, Chandak GR, Xi B. FTO gene variant and risk of hypertension: A meta-analysis of 57,464 hypertensive cases and 41,256 controls. Metabolism. 2014;63(5):633-9.

3. Liu C, Mou S, Pan C. The FTO gene rs9939609 polymorphism predicts risk of cardiovascular disease: a systematic review and meta-analysis. PLOS ONE. 2013;8(8):e71901.

4. Loos RJ, Yeo GS. The bigger picture of FTO the first GWAS-identified obesity gene. Nat Rev Endoc. 2014;10(1):51-61.

5. Frayling TM, Timpson NJ, Weedon MN, Zeggini E, Freathy RM, Lindgren CM, et al. A common variant in the FTO gene is associated with body mass index and predisposes to childhood and adult obesity. Science. 2007; 316(5826):889-94.

6. Rauhio A, Uusi-Rasi K, Nikkari ST, Kannus P, Sievänen H, Kunnas T. Association of the FTO and ADRB2 genes with body composition and fat distribution in obese women. Maturitas. 2013;76(2):165-71.

7. Andreasen CH, Stender-Petersen KL, Mogensen MS, Torekov SS, Wegner L, Andersen $\mathrm{G}$, et al. Low physical activity accentuates the effect of the FTO rs9939609 polymorphism on body fat accumulation. Diabetes. 2008;57(1):95-101.

8. Liu G, Zhu H, Lagou V, Gutin B, Stallmann-Jorgensen IS, Treiber FA, et al. FTO variant rs9939609 is associated with body mass index and waist circumference, but not with energy intake or physical activity in Europeanand African-American youth. BMC Med Genet. 2010;11(1):57.

9. Sonestedt E, Gullberg B, Ericson U, Wirfält E, Hedblad B, Orho-Melander M. Association between fat intake, physical activity and mortality depending on genetic variation in FTO. Int J Obesity. 2011;35(8):1041-9.

10. Matsuo T, Nakata Y, Hotta K, Tanaka K. The FTO genotype as a useful predictor of body weight maintenance: Initial data from a 5-year follow-up study. Metabolism. 2014;63(7):912-7.

11. Tanofsky-Kraff M, Han JC, Anandalingam K, Shomaker LB, Columbo KM, Wolkoff $L E$, et al. The FTO gene rs9939609 obesity-risk allele and loss of control over eating. Am J Clin Nutr. 2009;90(6):1483-8. 
12. Jess T, Zimmermann E, Kring SII, Berentzen T, Holst C, Toubro S, et al. Impact on weight dynamics and general growth of the common FTO rs9939609: a longitudinal Danish cohort study. Int J Obesity. 2008; 32(9):1388-94.

13. Livshits G, Malkin I, Moayyeri A, Spector TD, Hammond CJ. Association of FTO gene variants with body composition in UK twins. Ann Hum Genet. 2012;76(5):333-41.

14. Phillips CM, Kesse-Guyot E, McManus R, Hercberg S, Lairon D, Planells R, et al. High Dietary Saturated Fat Intake Accentuates Obesity Risk Associated with the Fat Mass and Obesity-Associated Gene in Adults. J Nutr. 2012; 142(5):824-31.

15. Corella D, Arnett DK, Tucker KL, Kabagambe EK, Tsai M, Parnell LD, et al. A high intake of saturated fatty acids strengthens the association between the fat mass and obesity-associated gene and BMI. J Nutr. 2011;141(12):2219-25.

16. Zhang X, Qi Q, Zhang C, Smith SR, Hu FB, Sacks FM, et al. FTO Genotype and 2-Year Change in Body Composition and Fat Distribution in Response to Weight-Loss Diets The POUNDS LOST Trial. Diabetes. 2012;61(11):3005-11.

17. Huang T, Qi Q, Li Y, Hu FB, Bray GA, Sacks FM, et al. FTO genotype, dietary protein, and change in appetite: the Preventing Overweight Using Novel Dietary Strategies trial. Am J Clin Nutr. 2014;99(5):1126-30.

18. Kilpeläinen TO, Qi L, Brage S, Sharp SJ, Sonestedt E, Demerath E, et al. Physical activity attenuates the influence of FTO variants on obesity risk: a meta-analysis of 218,166 adults and 19,268 children. PLoS Med. 2011;8(11):e1001116.

19. Rankinen T, Rice T, Teran-Garcia M, Rao DC, Bouchard C. FTO Genotype Is Associated With Exercise Training-induced Changes in Body Composition. Obesity. 2010;18(2):322-6.

20. Muc M, Padez C, Manco L. Influence of physical activity on the association between the FTO variant rs9939609 and adiposity in young adults. Am J Hum Biol. 2015;27(5):734-8.

21. Eynon N, Nasibulina ES, Banting LK, Cieszczyk P, Maciejewska-Karlowska A, Sawczuk M, et al. The FTO A/T polymorphism and elite athletic performance: a study involving three groups of European athletes. PLOS ONE. 2013;8(4):e60570.

22. Heffernan SM, Kilduff LP, Erskine RM, Day SH, McPhee JS, McMahon GE, et al. Association of ACTN3 R577X but not ACE I/D gene variants with elite rugby union player status and playing position. Physiol Genomics. 2016; 48(3):196-201.

23. Heffernan SM, Kilduff LP, Day SH, Pitsiladis YP, Williams AG. Genomics in rugby union: A review and future prospects. Eur J Sport Sci. 2015;15(6):460-8.

24. Baecke JA, Burema J, Frijters J. A short questionnaire for the measurement of habitual physical activity in epidemiological studies. Am J Clin Nutr. 1982; 36(5):936-42.

25. Reeves ND, Narici MV, Maganaris CN. Effect of resistance training on skeletal muscle-specific force in elderly humans. J Appl Physiol. 2004;96(3):885-92.

26. Behm D, St-Pierre D, Perez D. Muscle inactivation: assessment of interpolated twitch technique. J Appl Physiol. 1996;81(5):2267-73.

27. Erskine RM, Morse Cl, Day SH, Williams AG, Onambele-Pearson GL. The human patellar tendon moment arm assessed in vivo using dual-energy $\mathrm{X}$ ray absorptiometry. J Biomech. 2014;47(6):1294-8.

28. Narici M, Landoni L, Minetti A. Assessment of human knee extensor muscles stress from in vivo physiological cross-sectional area and strength measurements. Eur J Appl Physiol O. 1992;65(5):438-44.

29. Reeves ND, Maganaris CN, Narici MV. Ultrasonographic assessment of human skeletal muscle size. Eur J Appl Physiol. 2004;91(1):116-8.

30. Morse $\mathrm{Cl}$, Degens $\mathrm{H}$, Jones DA. The validity of estimating quadriceps volume from single MRI cross-sections in young men. Eur J Appl Physiol. 2007;100(3):267-74.

31. Owen NJ, Watkins J, Kilduff LP, Bevan HR, Bennett MA. Development of a criterion method to determine peak mechanical power output in a countermovement jump. J Strength Cond Res. 2014;28(6):1552-8.

32. Lahiri DK, Nurnberger II. A rapid non-enzymatic method for the preparation of HMW DNA from blood for RFLP studies. Nucleic Acids Res. 1991;19(19):5444.

33. Cahill N, Lamb K, Worsfold P, Headey R, Murray S. The movement characteristics of English Premiership rugby union players. J Sports Sci. 2013;31(3):229-37.

34. Roberts SP, Trewartha G, Higgitt RJ, El-Abd J, Stokes KA. The physical demands of elite English rugby union. J Sports Sci. 2008;26(8):825-33.

35. Jones MR, West DJ, Crewther BT, Cook CJ, Kilduff LP. Quantifying positional and temporal movement patterns in professional rugby union using global positioning system. Eur J Sport Sci. 2015;15(6):488-96.
36. Benjamini Y, Hochberg Y. Controlling the false discovery rate: a practical and powerful approach to multiple testing. J R Stat Soc. 1995;57(1):289-300.

37. Smart DJ, Hopkins WG, Gill ND. Differences and changes in the physical characteristics of professional and amateur rugby union players. J Strength Cond Res. 2013;27(11):3033-44

38. Sedeaud A, Marc A, Schipman J, Tafflet M, Hager J-P, Toussaint J-F. How they won Rugby World Cup through height, mass and collective experience. Brit J Sports Med. 2012;46:580-4.

39. Crewther B, Kilduff L, Cook C, Cunningham D, Bunce P, Bracken R, et al. Scaling strength and power for body mass differences in rugby union players. J Sports Med Phys Fitness. 2012;52(1):27-32.

40. Grunnet LG, Nilsson E, Ling C, Hansen T, Pedersen O, Groop L, et al. Regulation and function of FTO mRNA expression in human skeletal muscle and subcutaneous adipose tissue. Diabetes. 2009;58(10):2402-8.

41. Wåhlén K, Sjölin E, Hoffstedt J. The common rs9939609 gene variant of the fat mass-and obesity-associated gene FTO is related to fat cell lipolysis. J Lipid Res. 2008;49(3):607-11.

42. Smemo S, Tena JJ, Kim K-H, Gamazon ER, Sakabe NJ, Gómez-Marín C, et al. Obesity-associated variants within FTO form long-range functional connections with IRX3. Nature. 2014;507(7492):371-5.

43. Schulz TJ, Huang TL, Tran TT, Zhang H, Townsend KL, Shadrach JL, et al. Identification of inducible brown adipocyte progenitors residing in skeletal muscle and white fat. P Natl A Sci. 2011;108(1):143-8.

44. Bellefroid EJ, Kobbe A, Gruss P, Pieler T, Gurdon JB, Papalopulu N. Xiro3 encodes a Xenopus homolog of the Drosophila Iroquois genes and functions in neural specification. EMBO J. 1998:17(1):191-203.

45. Chen J-A, Huang Y-P, Mazzoni EO, Tan GC, Zavadil J, Wichterle H. Mir-17-3p controls spinal neural progenitor patterning by regulating Olig2//rx3 crossrepressive loop. Neuron. 2011;69(4):721-35.

46. Lamas NJ, Johnson-Kerner B, Roybon L, Kim YA, Garcia-Diaz A, Wichterle H, et al. Neurotrophic requirements of human motor neurons defined using amplified and purified stem cell-derived cultures. PLOS ONE. 2014;9(10):e110324.

47. Missitzi J, Geladas N, Klissouras V. Genetic variation of maximal velocity and EMG activity. Int J Sports Med. 2008;29(3):177-81.

48. Rosskopf D, Schwahn C, Neumann F, Bornhorst A, Rimmbach C, Mischke M, et al. The growth hormone-IGF-I axis as a mediator for the association between FTO variants and body mass index: results of the Study of Health in Pomerania. Int J Obesity. 2011;35(3):364-72.

49. Sharples AP, Hughes DC, Deane CS, Saini A, Selman C, Stewart CE. Longevity and skeletal muscle mass: the role of IGF signalling, the sirtuins, dietary restriction and protein intake. Aging Cell. 2015;14(4):511-23.

50. Bucci L, Yani SL, Fabbri C, Bijlsma AY, Maier AB, Meskers CG, et al. Circulating levels of adipokines and IGF-1 are associated with skeletal muscle strength of young and old healthy subjects. Biogerontology. 2013;14(3):261-72.

51. Barbieri M, Ferrucci L, Ragno E, Corsi A, Bandinelli S, Bonafè M, et al. Chronic inflammation and the effect of IGF-I on muscle strength and power in older persons. Am J Physiol Endocrinol Met. 2003;284(3):E481-7.

\section{Submit your next manuscript to BioMed Central and we will help you at every step:}

- We accept pre-submission inquiries

- Our selector tool helps you to find the most relevant journal

- We provide round the clock customer support

- Convenient online submission

- Thorough peer review

- Inclusion in PubMed and all major indexing services

- Maximum visibility for your research

Submit your manuscript at www.biomedcentral.com/submit 